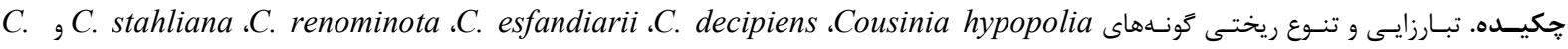

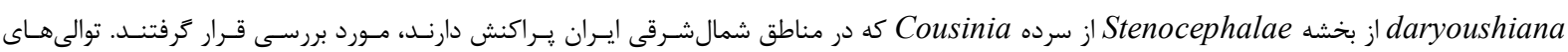

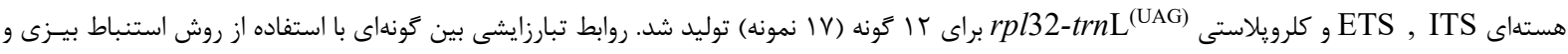

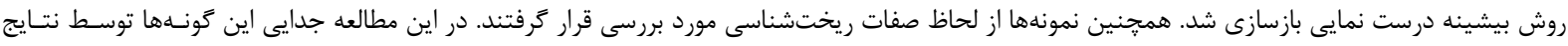

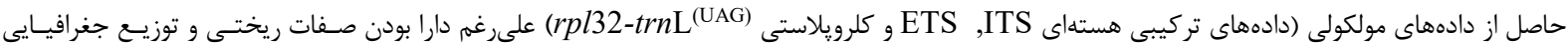

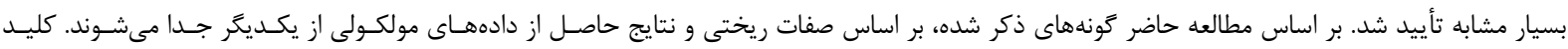

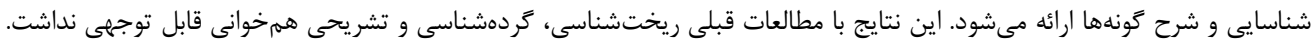
وازههاى كليدى. توزيع جغرافيايى، توالىهاى كلرويلاستى، توالىهاى هستهاى ، روش استنباط بيزى، صفات ريختى

\title{
Molecular phylogeny and taxonomy of species of Cousinia section Stenocephalae (Asteraceae) in NE of Iran
}

\section{Simin Kalouti ${ }^{1}$, Shahrokh Kazempour Osaloo ${ }^{1,4}$, Farideh Attar $^{2,4}$, Alfonso Susanna ${ }^{3}$ \& Núria Garcia-Jacas $^{3}$}

${ }^{1}$ Department of Plant Biology, Faculty of Biological Sciences, Tarbiat Modares University, Tehran, Iran; ${ }^{2}$ Central Herbarium, School of Biology, College of Science, University of Tehran, Tehran, Iran; ${ }^{3}$ Botanic Institute of Barcelona (CSIC-ICUB), Pg. del Migdia s.n., 08038 Barcelona, Spain, ${ }^{4}$ Center of Excellence in Phylogeny of Living Organisms, University of Tehran, Tehran, Iran

Correspondent author: Shahrokh Kazempour Osaloo, skosaloo@modares.ac.ir

\begin{abstract}
In this study, the phylogeny and morphological variation of 6 species of the genus Cousinia sect. Stenocephalae, i.e., C. hypopolia, C. decipiens, C. esfandiarii, C. renominata, C. stahliana and C. daryoushiana, distributed in NE regions of Iran, were investigated. ITS, ETS and rpl32-trnL (UAG) sequences for 12 species (17 specimens) were generated. Phylogenetic interspecies relationships were constructed by Bayesian method and likelihood analysis. The specimens were also investigated in terms of morphological characters. Despite very similar morphological characters and geographical distributions, the separation of these species was confirmed by the obtained results of the molecular data (combined data of plastid and nuclear sequences). On the basis of the present study, the above-mentioned species were almost separated from each other by morphological characters and molecular data. A diagnostic key and the description of these species were also presented. These results did not conform with the previous palynological and anatomical studies of the species.
\end{abstract}

Keywords. Bayesian analysis, chloroplast sequences, geographical distribution, morphological characters, nuclear sequences 
1933; Rechinger, 1972, 1979 (193). دامنه يراكنش گونـههـا در

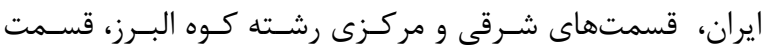

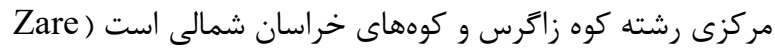
(et al., 2013

اين بخشه است (Ghaffari \& Djavadi, 1998).

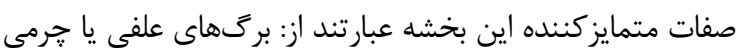

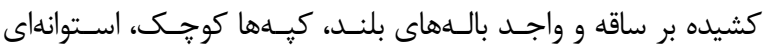

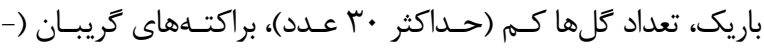

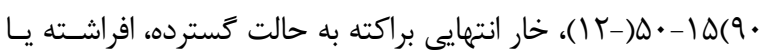

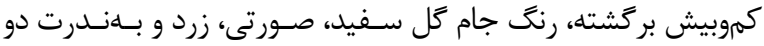

رنگ (Saber, 2005; Djavadi \& Attar, 2006)

Ghaffari et al., 1985; ) تـاكنون مطالعـات كرومـوزومى (2010)

Ghaffari \& Djavadi 1998; Ghaffari et al., 2006; Djavadi, 2007; Djavadi \& Attar 2010; Djavadi, Saber, ) 2012; Bordbar et al., 2017

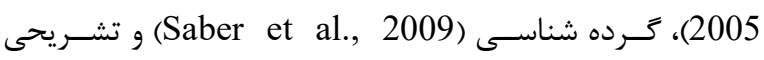
(Saber, 2005) بر روى كونههاى اين بخشه صورت كرفته است.

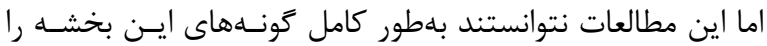

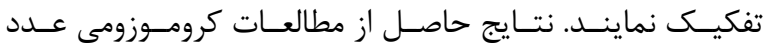

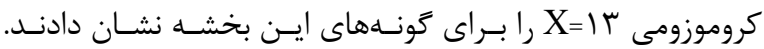

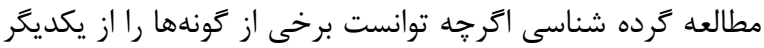

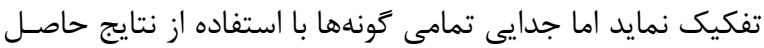
امكان يذير نبود. صفات تشريحى بهدست آمده در مطالعه ساختار

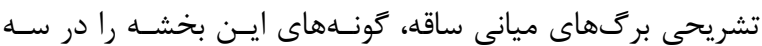

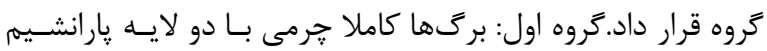

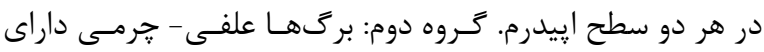

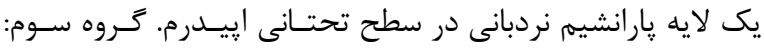

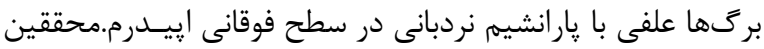

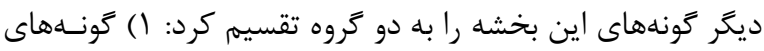

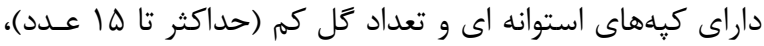

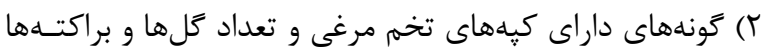

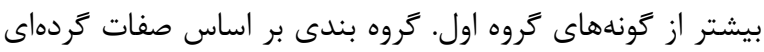

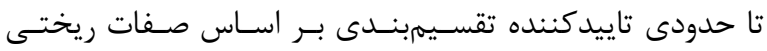

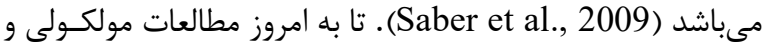
تبارزايشى براى تعيسين محـدوده كونـههاى ايـن بخشـهـ صـورت

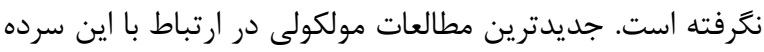
Arctium- بلهنظور تعيين مرزهاى سرده و زير سرده كمـيلكس nrDNA ITS با Cousinia كلرويلاستى

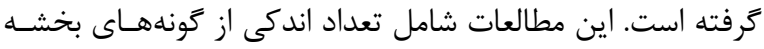

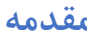
هزارخار (Cousinia Cass) يكسى از سـردهاى مهـم ناحيـهـ

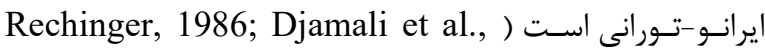

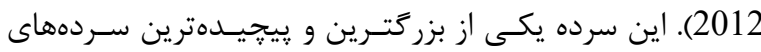
تيره كاسـنيان Asteraceae Martinov بـوده و دومسين سـرده

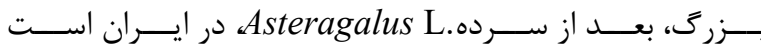
Rechinger, 1972,1979; Tscherneva et al.; 2005; ) Cousinia .(Djavadi \& Attar, 2006

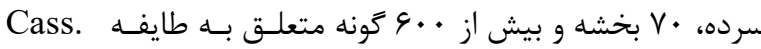
وCardueae

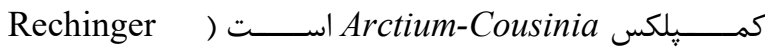
1972,1979; Tscherneva, 1962; Susanna \& Garcia.Jacas, 2007; López-Viyallonga et al., 2009, 2011

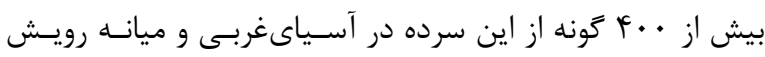

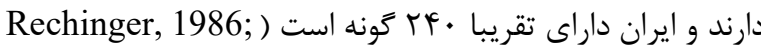
Knapp, 1987; Djavadi \& Attar, 2010; Zare et al., 2013). مهممترين مركز تنوع ايـن سـرده سـرزمينهاى كوهسـتانى

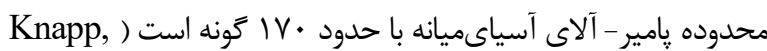

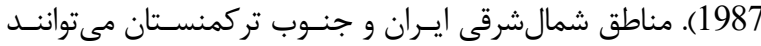

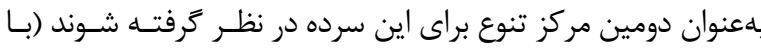

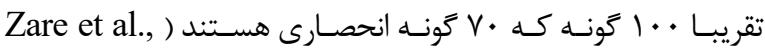
2013). بر طبق مطالعه اخير كه بر روى براكنش اين سرده در ايـران

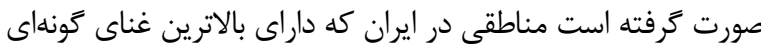

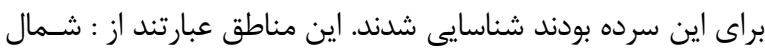

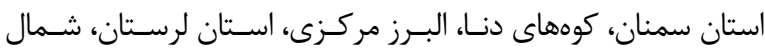
غربى ايران و كوههاى كيه داغ (Zare et al., 2013).

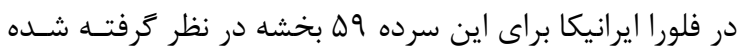

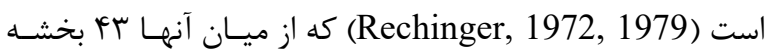

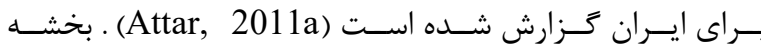
Stenocephalae Bunge بخشههاى Alpinae Bunge , Cynaroidae Bunge، سـومين ترن

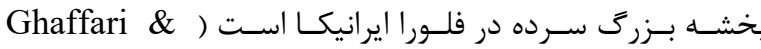

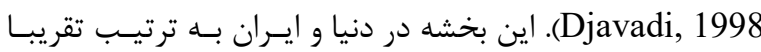

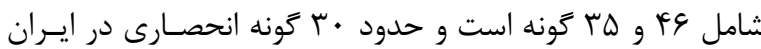
Attar et al., 2005; Djavadi \& Attar, 2006; Attar, ) (2011b; Saber et al., 2009

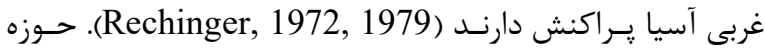

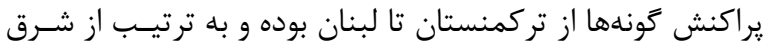

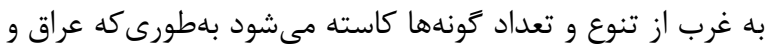

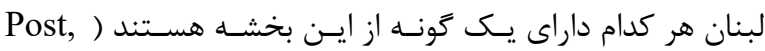


ارائه شرح گونهها و كليد شناسايى براى گونههايى از ايـن بخشـهـ كه در شمالشرقى ايران يراكنش دارند.

\section{مواد و روشها}

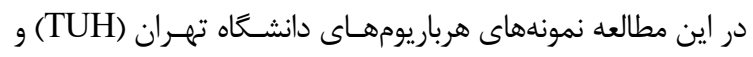
موسسه تحقيقات جنكلها و مراتع كشور (TARI) مورد بررسى قرار مرار

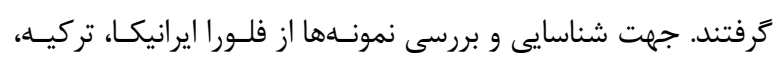

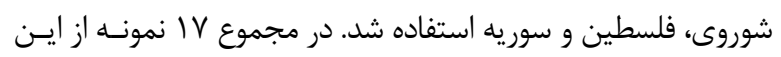

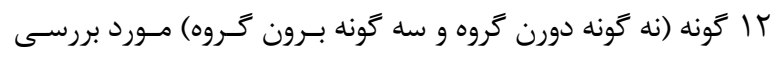

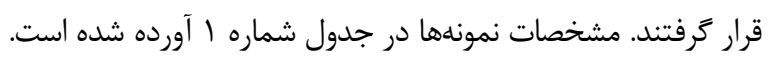

استخراج SNA

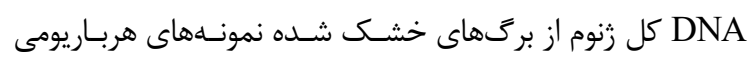

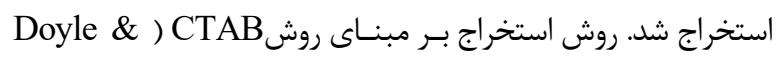

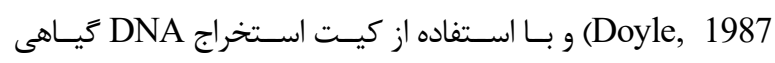
انجام شد. (Exgene TM Plant SV mini)

واكنش زنجيرهاى يليمراز

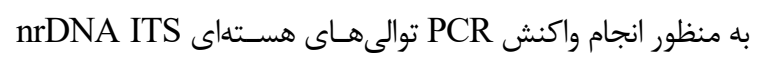

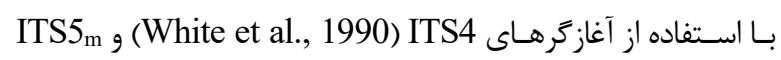
S) MF-F • بر اساس برنامــ (Sang et al., 1995) •

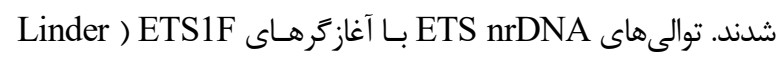
Marcos ) AST1F ،(Lee et al., 2002) L-ETS ،(et al., 2000 ETS-COUF و ( \& B Baldwin 2001

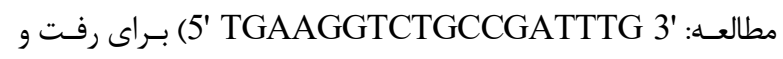
آغازكرهـاى 18S- (Linder et al., 2000) 18S-2L ETSR Baldwin ) AST1R , (Marcos \& Baldwin, 2001)ETSR (\& Marcos, 1998

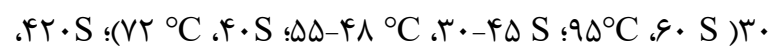

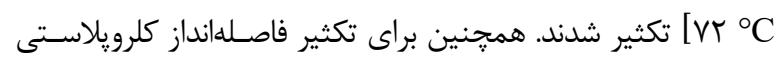

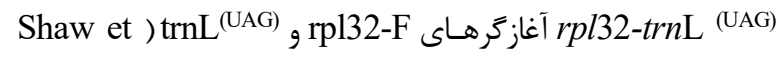
S (al., 2007 .9.

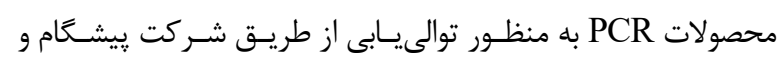

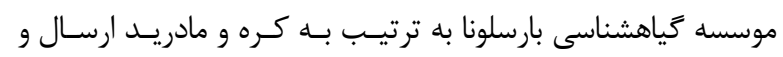
توسط شركت Macrogen تعيين توالى كرديد.

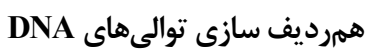
López-Viyallonga et al., 2009, 2011 بـر اسـاس مطالعـات سوناي كونسهاى A. lappa عنوان برون گروه انتخاب شدند. توالىهاى بهدست آمده با استفاده از
López-Viyallonga et al., 2009, ) استـ Stenocephalae 2011). تحليلهاى تبارزايشى نشان داد كه به دليل سـن نسـبتا

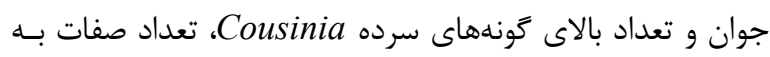

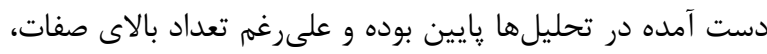

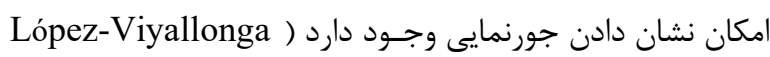
.et al. 2009 در بيشتر موارد شناسايى كونههاى اين بخشه با مشكل روبـرو

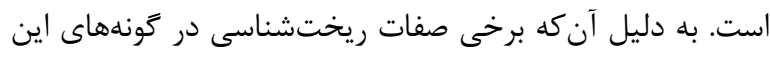

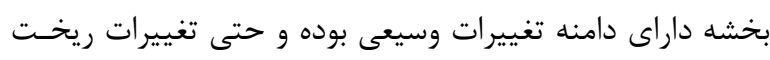

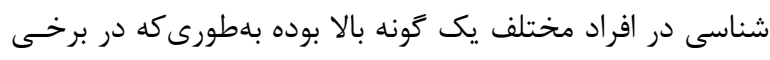

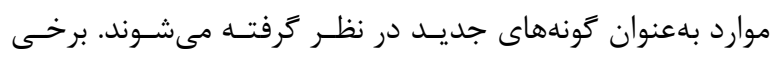

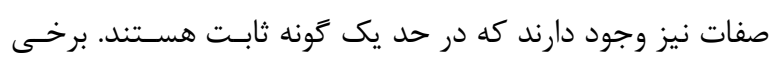

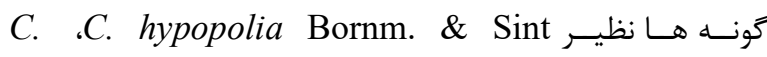
C. esfandiarii Rech.f. \& decipiens Boiss. \& Buhse C. stahliana Bornm. ،C. renominota Rech.f. ،Aellen C. daryoushiana Parsa \& \& Gauba

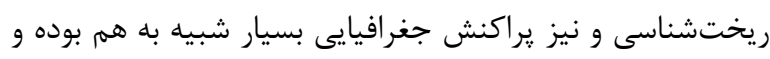

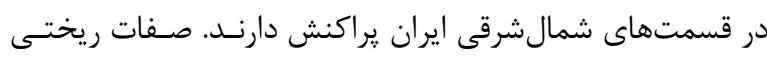

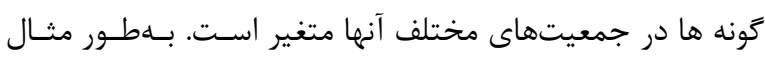

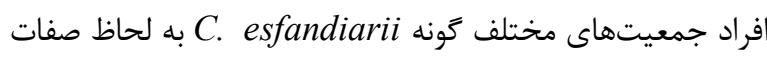

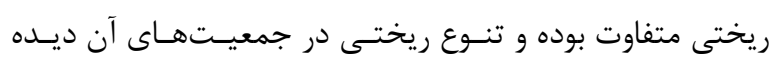

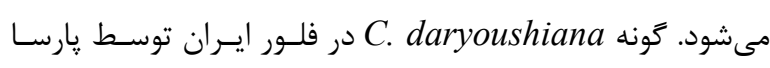

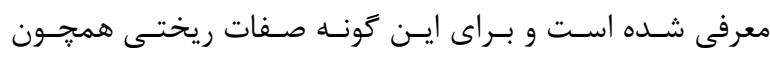

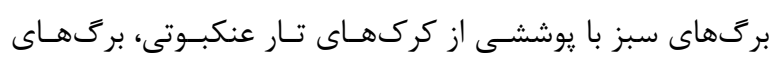

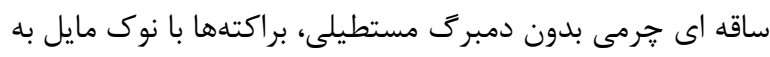

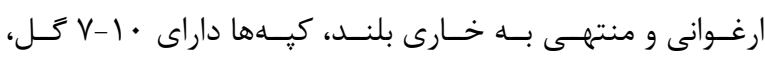

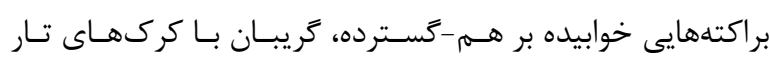

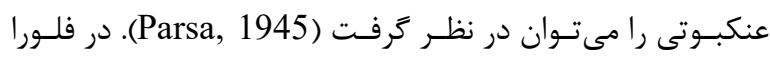

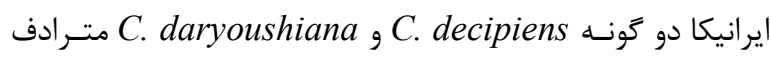

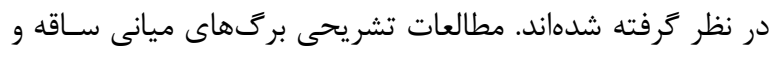

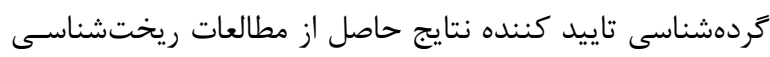

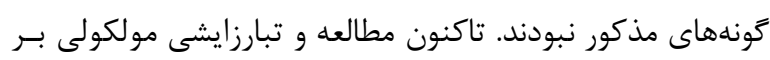

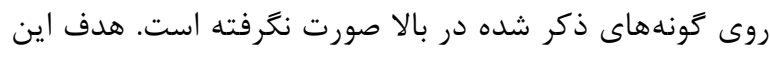

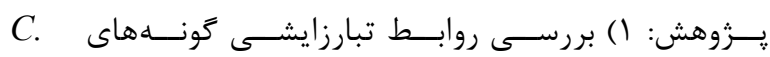
C. C. esfandiarii ،C. decipiens .hypopolia C. daryoushiana, C. stahliana renominota

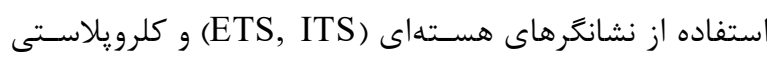

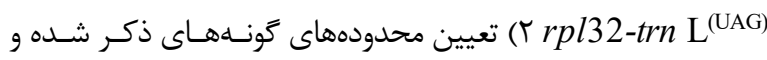

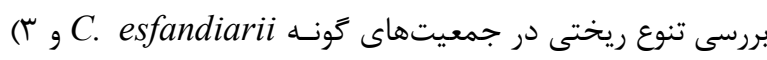


جدول ا- نمونهها، مكان و شماره هرباريومى آرايههاى مورد مطالعه.

Table 1. Accessions, locations and herbarium numbers of studied taxa.

\begin{tabular}{|c|c|c|}
\hline Accessions & Voucher Specimen & $\begin{array}{l}\text { GenBank accession No: } \\
\text { ITS/ETS/rpl32-trnL } \text { (UAG)/ }^{\text {(T) }}\end{array}$ \\
\hline Cousinia esfandiarii (1) Rech.f. \& Aellen & $\begin{array}{l}\text { Iran: Semnan: Shahrud, Gardaneh-ye Khosh Yeylagh, 65-68 } \\
\mathrm{km} \text { to Azadshahr, Saber \& Moazzeni } 34367 \text { (TUH) }\end{array}$ & LC530282/LC530299/LC530316 \\
\hline C. esfandiarii (2) Rech.f. \& Aellen & $\begin{array}{l}\text { Iran: Golestan: Golestan pass, } 65 \mathrm{~km} \text { to Bojnurd: Ghahreman } \\
\text { \& Attar } 21896 \text { (TUH) }\end{array}$ & LC530283/LC530300/LC530317 \\
\hline C. esfandiarii (3) Rech.f. \& Aellen & $\begin{array}{l}\text { Iran: Semnan: Shahrud, Tash, Ghahreman, Attar \& Mehdigholi } \\
27674 \text { (TUH) }\end{array}$ & LC530284/LC530301/LC530318 \\
\hline C. esfandiarii (4) Rech.f. \& Aellen & $\begin{array}{l}\text { Iran: Semnan: Shahmirzad to Fulad-Mahalleh, Ca. } 10 \mathrm{~km} \text { after } \\
\text { Molla-Deh to Hikoo Village, Attar \& Zamani } 38719 \text { (TUH) }\end{array}$ & LC530285/LC530302/LC530319 \\
\hline C. esfandiarii (5) Rech.f. \& Aellen & $\begin{array}{l}\text { Iran: Semnan: } 20 \mathrm{~km} \text { after Meyqan, Attar, Miratadzadinii \& } \\
\text { Rastegar } 45830(\mathrm{TUH})\end{array}$ & LC530286/LC530303/LC530320 \\
\hline C. esfandiarii (6) Rech.f. \& Aellen & $\begin{array}{l}\text { Iran: Gorgan: Between Azadshahr and Shahrud, after Farsian, } \\
\text { Assadi \& Azadi } 76128 \text { (TARI) }\end{array}$ & LC530287/LC530304/LC530321 \\
\hline C. decipiens Boiss. \& Buhse & $\begin{array}{l}\text { Iran: Golestan: Park Golesten, after Tang-e Rah to Bojnurd, } \\
\text { Ghahreman, Attar \& Mehdigholi } 25437 \text { (TUH) }\end{array}$ & LC530281/LC530298/LC530315 \\
\hline C. renominata Rech.f. & $\begin{array}{l}\text { Iran: Khorassan: Kalaleh to Maraveh Tappeh, Gardaneh-ye } \\
\text { Chenaran prope: Saber \& Moazzeni } 34368 \text { (TUH) }\end{array}$ & LC530288/LC530305/LC530322 \\
\hline C. stahliana Bornm. \& Gauba & $\begin{array}{l}\text { Iran: Khorassan: } 30 \mathrm{~km} \text { to Bojnurd from Shirvan, Attar \& } \\
\text { Zamani } 43027 \text { (TUH) }\end{array}$ & LC530289/LC530306/LC530323 \\
\hline C. hypopolia Bornm. \& Sint & $\begin{array}{l}\text { Iran: Khorassan: Between Bojnurd and Chaman Bid, } \\
\text { Ghahreman \& Attar 21904 (TUH) }\end{array}$ & LC530290/LC530307/LC530324 \\
\hline C. daryoushiana Parsa & $\begin{array}{l}\text { Iran: Gorgan: On the road from Bojnurd to Shahpasand, } \\
\text { Chaman-Bid: Assadi \& Maassoumi } 21447 \text { (TARI) }\end{array}$ & LC530291/ LC530308/LC530325 \\
\hline C. stenocephala Boiss. & $\begin{array}{l}\text { Iran: Kermanshah: } 35 \mathrm{~km} \text { to Gilane Gharb from Ghasreshirin, } \\
\text { Attar \& Hamzehee } 45544 \text { (TUH) }\end{array}$ & LC530292/LC530309/LC530326 \\
\hline C. cylindracea var. patula Heimer & $\begin{array}{l}\text { Iran: Zanjan: } 33 \mathrm{~km} \text { to Qaidar from Soltanieh, Zarre \& Saber } \\
34392 \text { (TUH) }\end{array}$ & LC530294/LC530311/LC530328 \\
\hline C. alexeenkoana Bornm. & $\begin{array}{l}\text { Iran: Hamedan: Soltan Bolagh, between Avaj and Razan, } \\
\text { Kharaghan, Djavadi \& Ghanbari 20376/3 (IRAN) }\end{array}$ & LC530293/LC530310/LC530327 \\
\hline A. umbrosum (Bunge) Kuntze & $\begin{array}{l}\text { Iran: Khorassan: road of Neyshabour, Binaloud, Ghahreman \& } \\
\text { Attar } 21914 \text { (TUH) }\end{array}$ & LC530280/LC530297/LC530314 \\
\hline A. amplissimum (Boiss.) Kuntze & $\begin{array}{l}\text { Iran: Khorassan: Hezar Masjed, Arab Chah, Attar\& Zaman } \\
43023 \text { (TUH) }\end{array}$ & LC530279/LC530296/LC530313 \\
\hline Arctium lappa $\mathrm{L}$. & $\begin{array}{l}\text { Iran: Mazandaran: Karaj-Chalus road. Pol-e Zanganeh, near } \\
\text { the river, Nazarian } 33071 \text { (TUH) }\end{array}$ & LC530278/LC530295/LC530312 \\
\hline
\end{tabular}

مجدد شاخهها استفاده شد. روش استنباط بيـزى بـه صـورت بـر

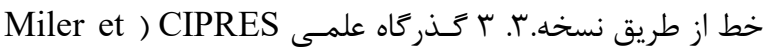
و و روش بيشينه درستنمايى از طريق نسخه اينترنتى (al., 2010

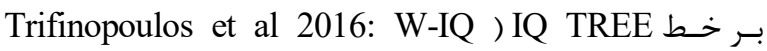
مورد تحليل قرار گرفتنـد. يـيش فـرض روش اسـتنباط

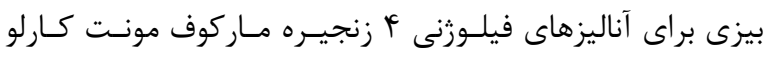

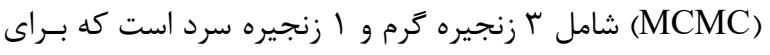

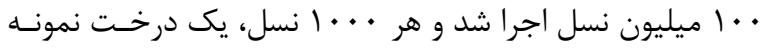

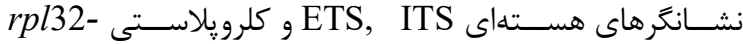
و إستفاده از نرمافزار trnL (Udgar, 2004) MUSCLE) Swofford, ) PAUP* 4.0b10 به صورت جشمى در نـرمافـزار 2002) همرديف سازى شدند. تحليل و بررسى هاى تبارزايشى

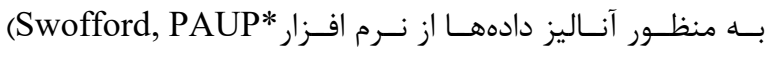

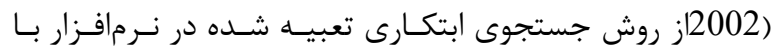

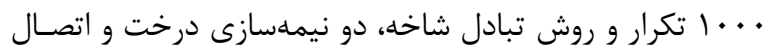




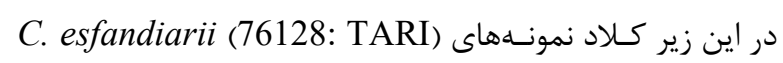

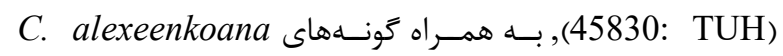

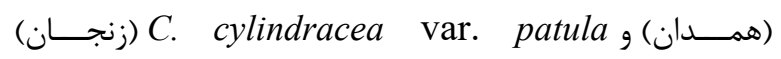

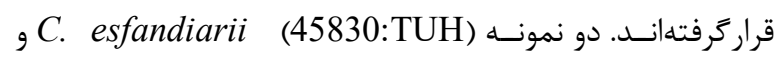
C. esfandiarii (76128: TARI)

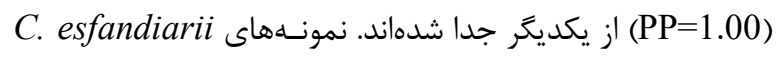
و (38719: TUH)، (21896: TUH)، (34367: TUH) جزئى از يك إلى تومى بوده و بـه صـورت حـل (27674: TUH)

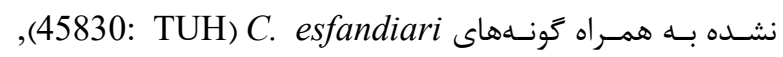
C. و C. alexeenkoana ، (76128: TARI)

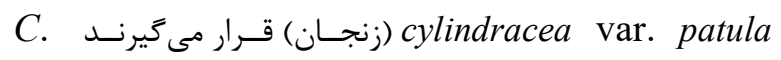
(38719: TUH) و با احتمـال (27674: TUH) esfandiarii .

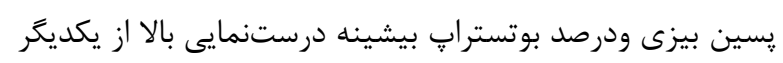

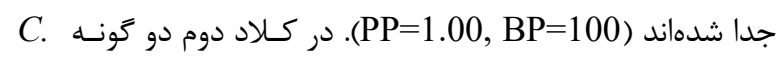
C. daryoushiana renominata

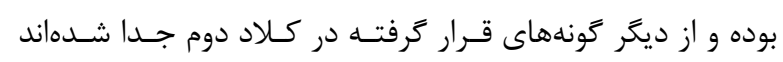
و C. decipiens بـا دو كونـا C. C. hypopolia .(PP:1 BP:78) C. stahliana

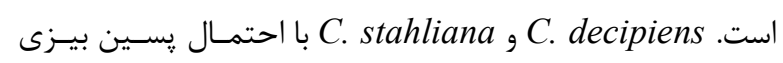
(PP=1.00)

\section{كليد شناسايى گَونه هاى مورد مطالعه}

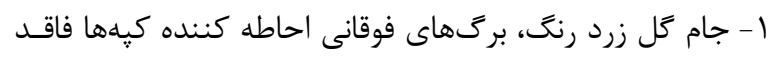

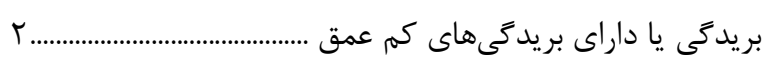

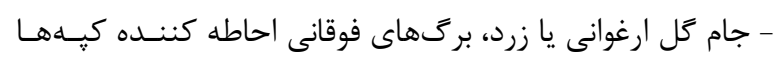
$\Delta$.. داراى بريدگى (تا عميق) ..

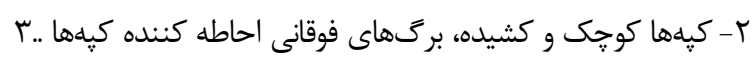

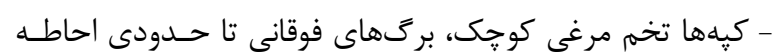

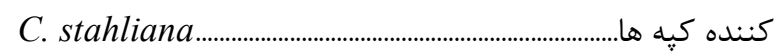

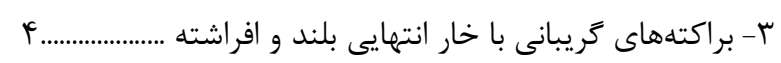

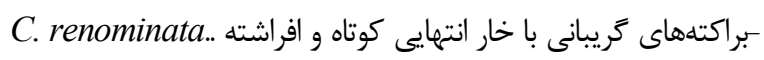

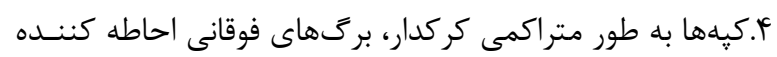

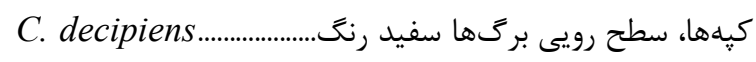

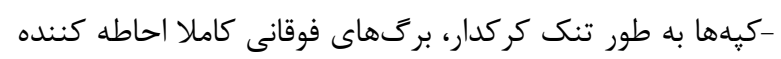

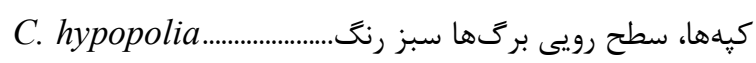

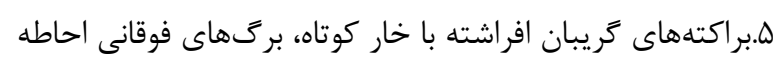

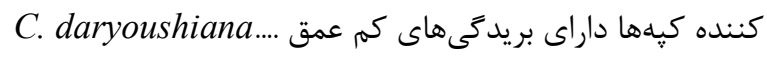
-براكتههاى گريبان افراشته تا برگشته با خار كوتاه تا بلند، برى

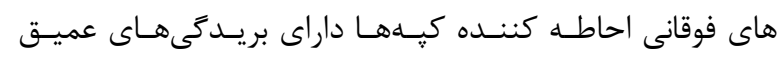
C. esfandiarii...
بردارى شد. يـس از يايــان اجــراى برنامـه، انحــــاف معيـار بــراى

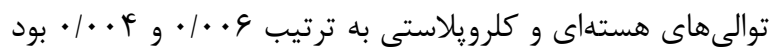

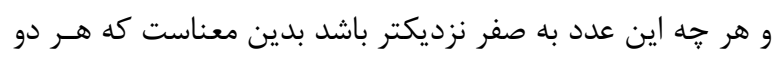

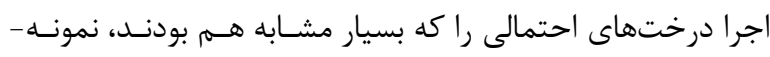

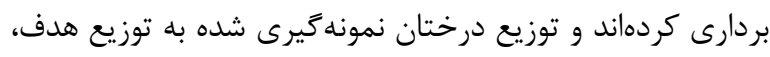

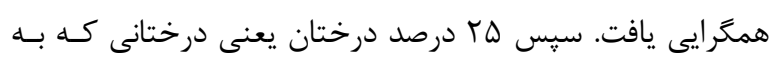

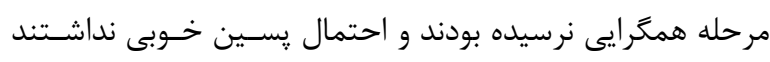
حذف شدند .مدل تكاملى براى دادههاى هستهاى ETS , ITS و

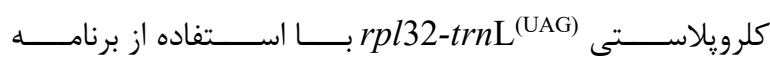
(Nylander, 2004) MrModeltest version 2.3 معيـار اطلاعـاتى ATR+ Akaike انتخــاب شـد. مـدل GTR ) بـراى دادههـاى حاصـل ازنشـانكرهاى هسـتهاى ITS و ETS و

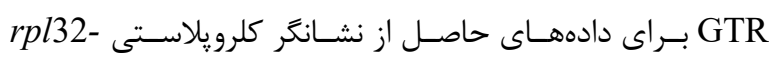

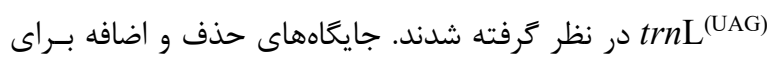

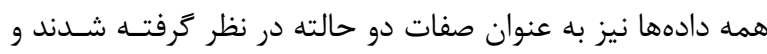

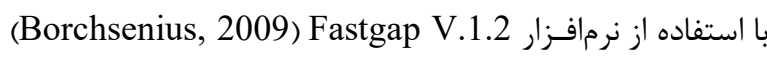
كد داده شدند. درختهاى تكاملى حاصل از دادههاى هسـتهاى و و

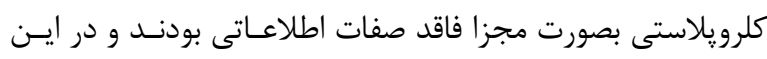

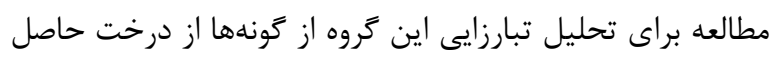

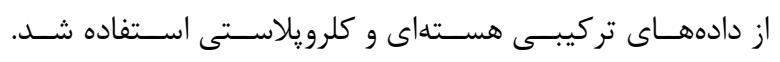
مشخصات دادههاى مولكولى در جدول شماره ب ارائه شده است.

نتايج

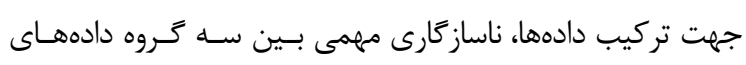

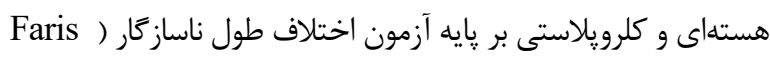
Swofford, ) PAUP* تعبيـه شـده در نـرم افـزار (et al. 1995

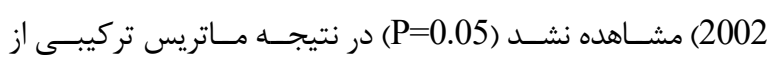

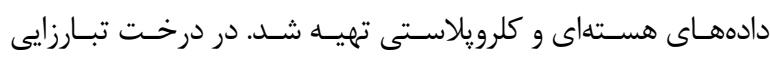

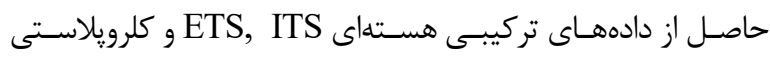

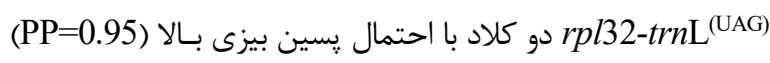

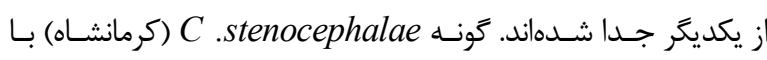
احتمال يسين بيزى بال |(PP=1.00) از اين كلادها جدا شده اسـت

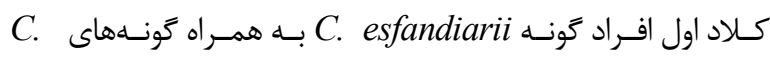
C. cylindracea var. patula (همــدان) alexeenkoana

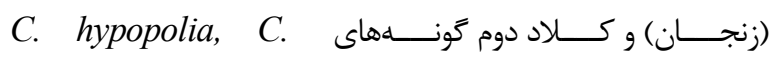
daryoushiana, C. decipiens, $C$. renominata, $C$. را شامل مىشوند. كلاد اول با احتمال ״سـين بيـزى بـالا

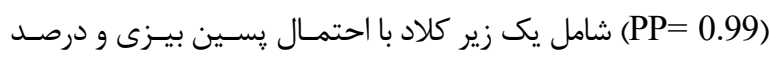
بوتستراب بيشينه درستنمايى بالا است (PP=1.00, BP=82). 
جدول r- مشخصات دادههاى مولكولى مورد تحليل و بررسى

Table 2. Summary statistics of the molecular data sets analysis.

\begin{tabular}{|c|c|c|c|c|}
\hline & $\begin{array}{l}\text { nrDNA } \\
\text { ITS }\end{array}$ & $\begin{array}{l}\text { nrDNA } \\
\text { ETS }\end{array}$ & cpDNA $^{\text {rpl32-trn }} \mathrm{L}^{(\mathrm{UAG})}$ & $\begin{array}{c}\text { Combined } \\
\text { ETS-ITS- rpl32-trnL } \\
\text { (UAG) }\end{array}$ \\
\hline Number of samples & 17 & 17 & 17 & 17 \\
\hline Number of characters & 645 & 1026 & 978 & 2649 \\
\hline GC contents mean (\%) & 30.35 & 25.4 & 13.65 & 21.95 \\
\hline $\begin{array}{l}\text { Parsimony-Informative Characters, included /not } \\
\text { included outgroups (PIC) }\end{array}$ & $59 / 19$ & $55 / 18$ & $21 / 7$ & $135 / 44$ \\
\hline $\begin{array}{l}\text { Conserved Characters included /not included } \\
\text { outgroups(McCauley) }\end{array}$ & $558 / 595$ & $753 / 781$ & 948/964 & $2259 / 2340$ \\
\hline $\begin{array}{l}\text { Variable Characters included /not included outgroups } \\
\text { (VC) }\end{array}$ & $85 / 46$ & $93 / 58$ & $29 / 12$ & 207/116 \\
\hline CI of MPTs (excluding uninformative characters) & 0.887 & 0.800 & 1.000 & 0.838 \\
\hline RI of MPTs (excluding uninformative characters) & 0.921 & 0.868 & 1.000 & 0.889 \\
\hline Overall Mean p-distance & 0.028 & 0.026 & 0.008 & 0.018 \\
\hline Best fitting model of evolution (BI analyze) & GTR+I & GTR+I & GTR & GTR +I \\
\hline Best fitting model of evolution (ML analyze) & - & - & - & $\mathrm{TIM} 2+\mathrm{F}+\mathrm{I}$ \\
\hline
\end{tabular}

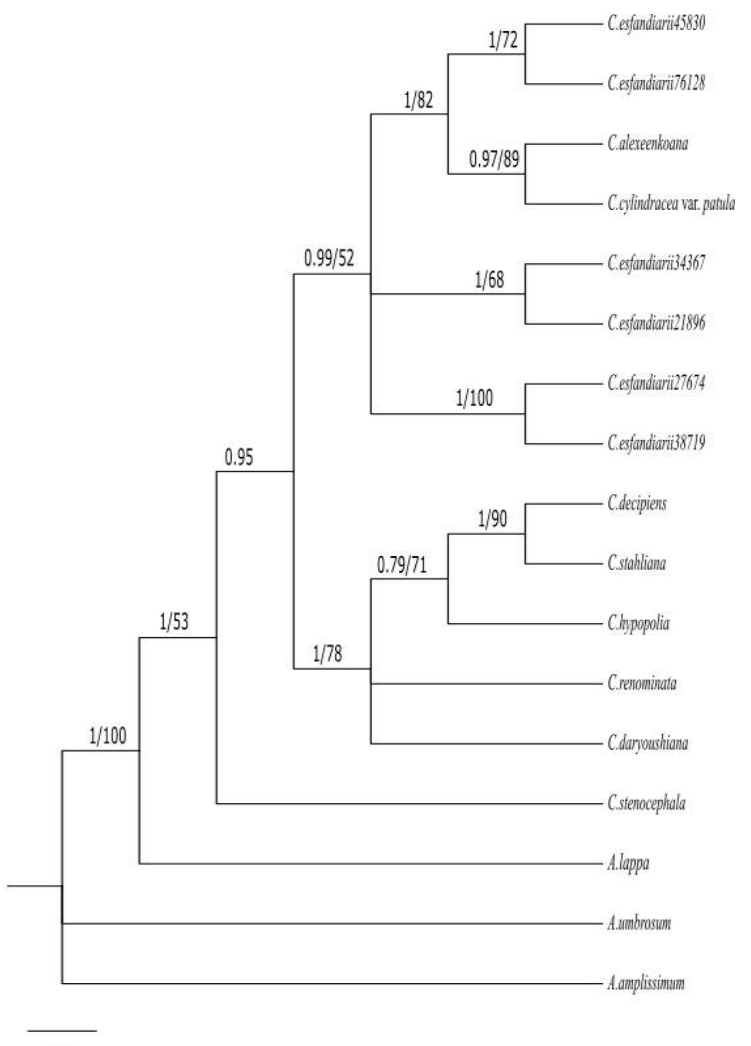

กQ

شكل ا- درخت حاصل از بازسازى روابط تبارزايشى دادهاى تركيبى هستهاى و كلرويلاسـتى (ITS + ETS +rpl32-trnL (UAG) بـر اسـاس روش اسـتنباط

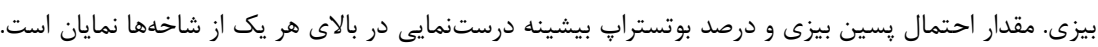

Figure 1. 50\% rule consensus tree resulting from Bayesian analysis of the combined dataset (ETS + ITS + rpl32- trn L ${ }^{(\mathrm{UAG})}$ ). Numbers above branches are posterior probability (PP) and bootstrap values from maximum likelihood, respectively. 


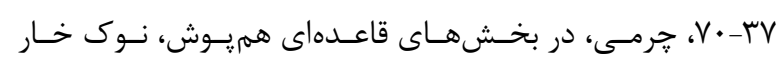

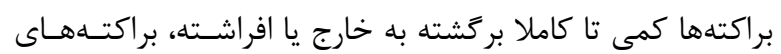

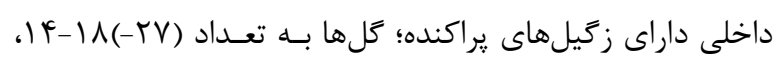

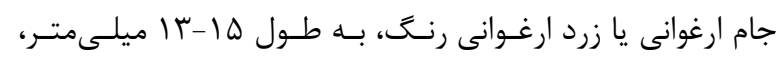

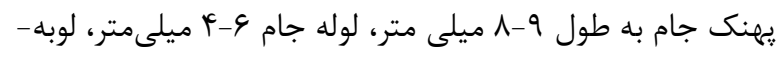

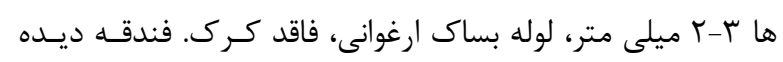

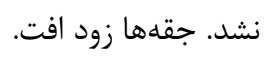

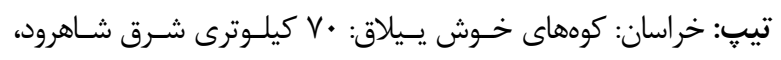

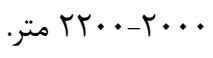
يراكنش عمومى: انحصارى ايران.

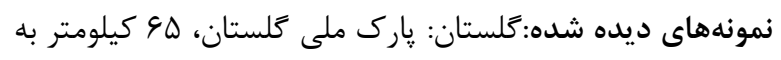

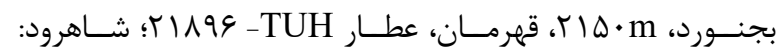

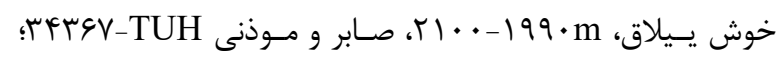

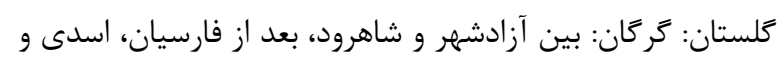

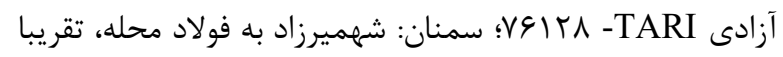

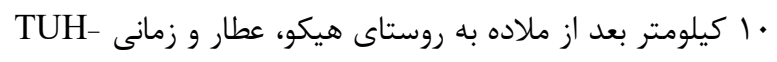

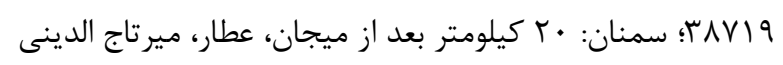

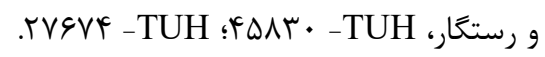

C.renominata Rech. f., Fl. Iranica. Vol.90, pp. 163. (1972, 1979). Syn.: C. Turkmenorum Bornm. \&

Gauba, Feddes Repert. 46: 277 (1939).

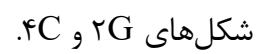

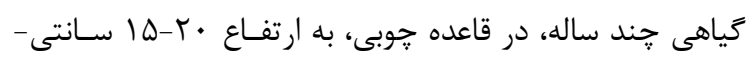

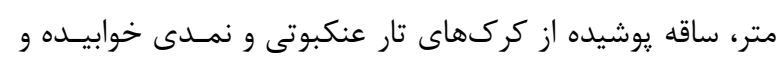

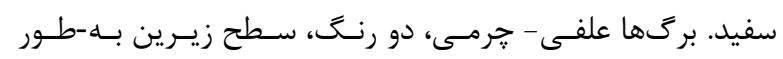

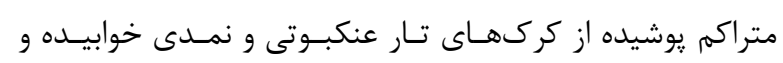

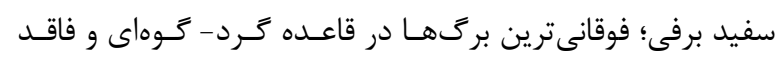

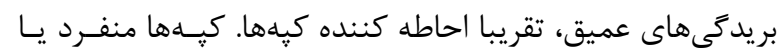

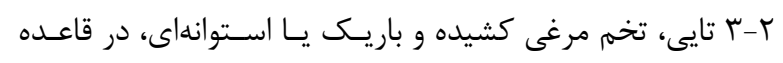

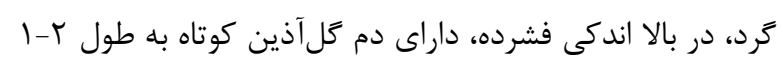

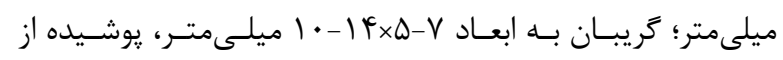

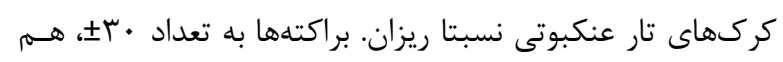

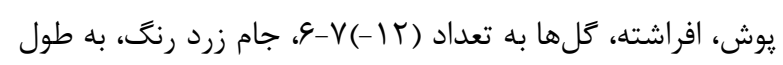

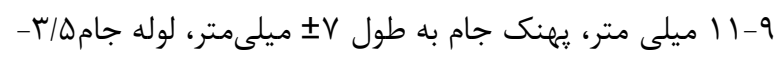

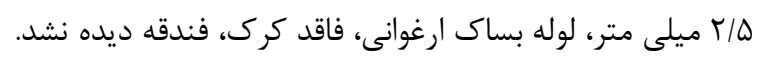

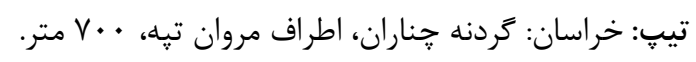
يراكنش عمومى: انحصارى ايران.

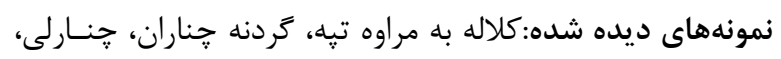

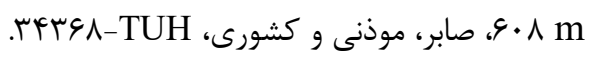

\section{شرح تونهها}

Cousinia decipiens Boiss. \& Buhse, Nouv. Mem. Soc. Nat. Mose. 12 (18): 125 (1860 ). Syn.: C.

hyrcanica Bornm., Osterr. Bot. Zeitschr. 75: 233 (1926), syn. nov. edescr. C. Daryoushiana Parsa, Kew Bull. 1948: 203 (1948).

شكلهاى

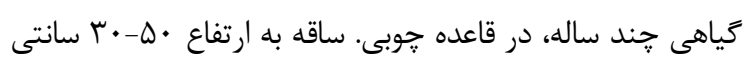

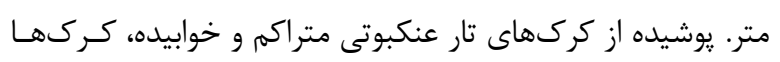

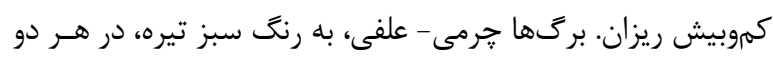

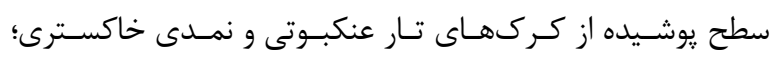

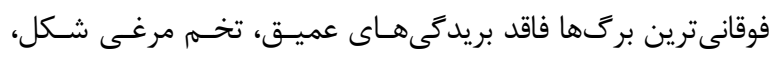

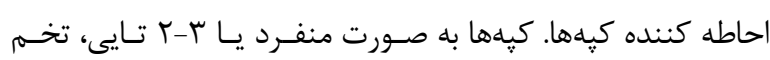

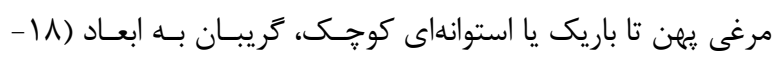

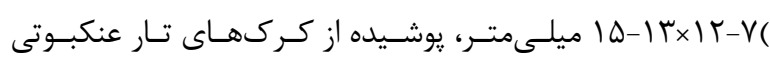

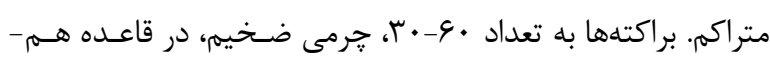

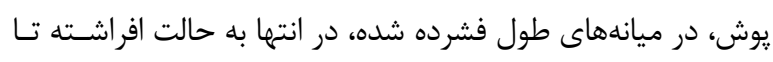

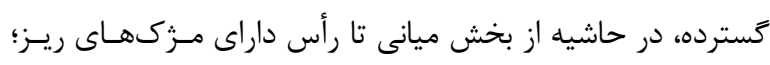

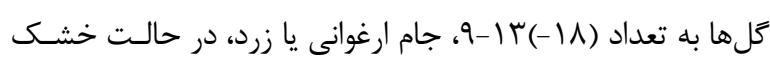

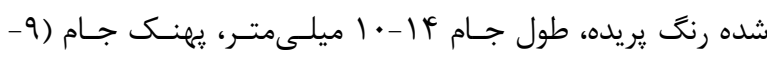

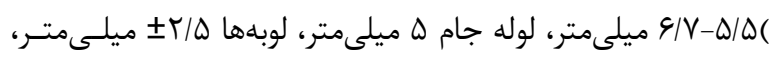

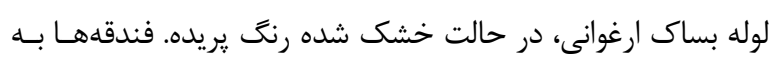
طول ب ميلىمتر، قهوهاى تيره، در قسمت فوقانى دندانهدار. تيب:كوههاى شاه كوه. ير اكنش عمومى: انحصارى ايران.

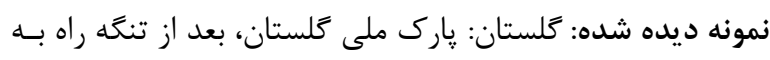

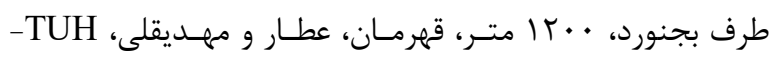
rQFHY

C. esfandiarii Rech. f. \& Aell., Ann. Nat. Mus. Wien 57: 75 (1950).

شكلهاى (A, B, C, D, E) و r (A, B, C, D, E, F).

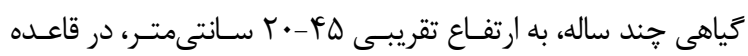

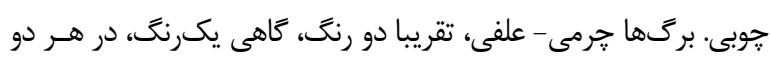

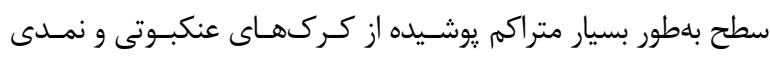

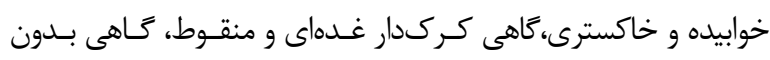

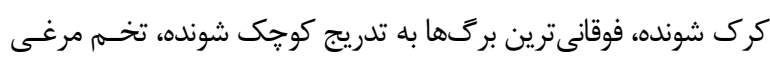

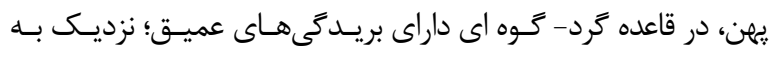

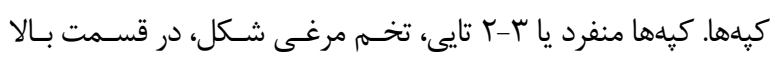

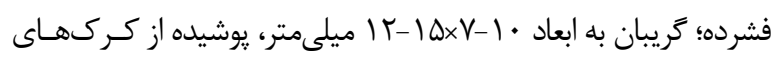

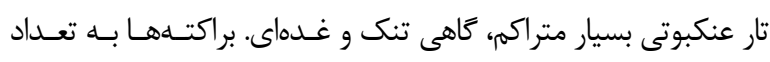


C. stahliana Bobnm. \& Gauba, Mitt. Thur. Bot. Ver. N. F. 47: 117 (1941). Syn.: G. hypopoliasensu K u 1 t., Herb. Fl. As. Med. nur. 45 et auct., nec Bornm. \& Sint.(1907).

$$
\text { شكلهاى rH, }
$$

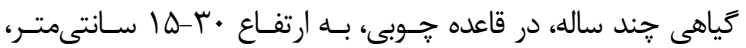

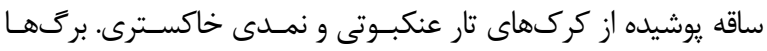

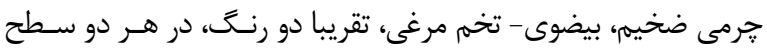

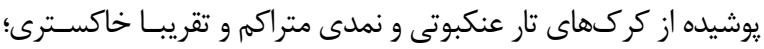

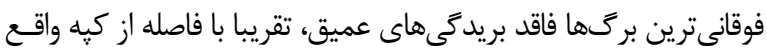

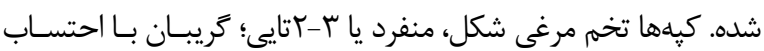

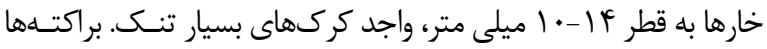

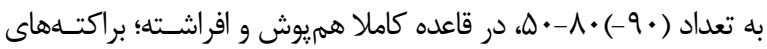

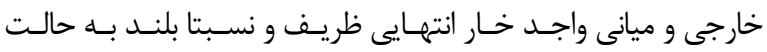

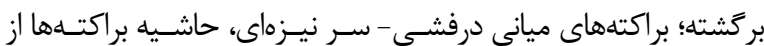

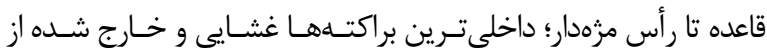

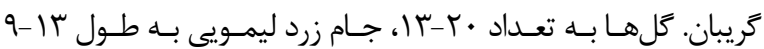

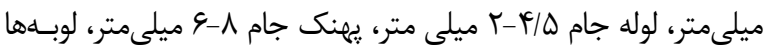

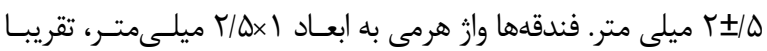
يهن و فشرده، قهوهاى رنت يريده، در قسمتهاى فوقانى گرد. C. daryushiana Parsa, Flore de l'Iran, vol. 3: 480 (1943).

شكل بركها سبز با يوششى از كركهاى تار عنكبوتى، برگهـاى سـاقهاى

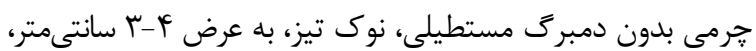
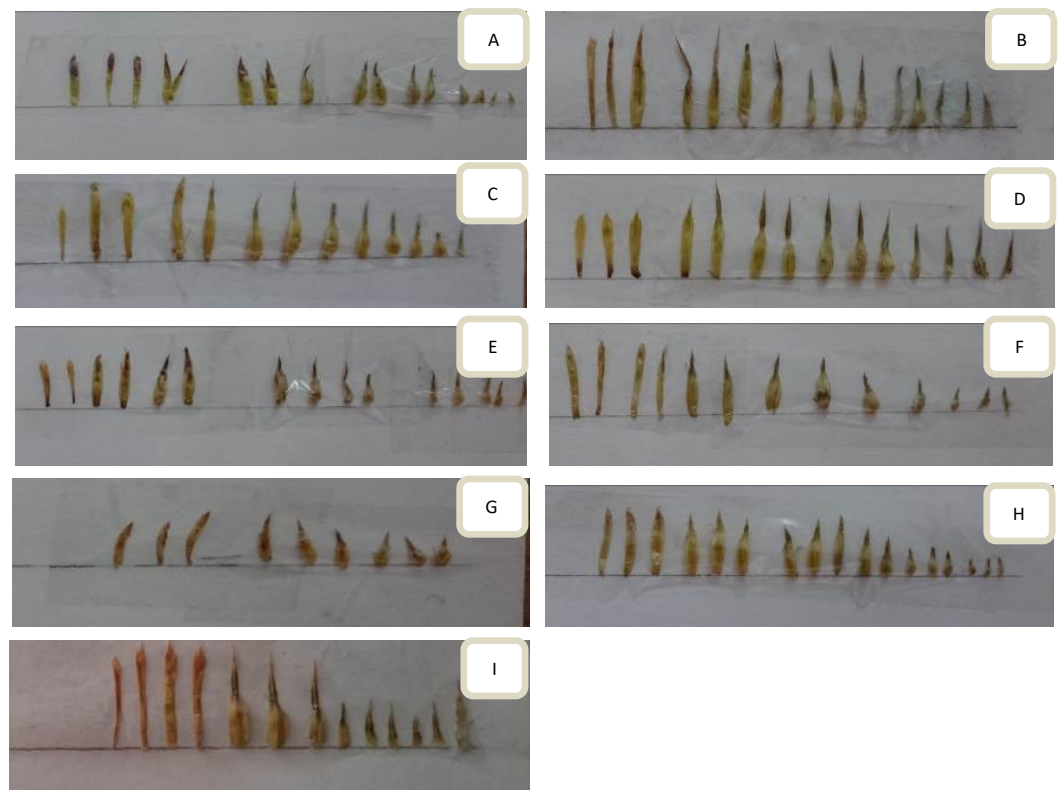

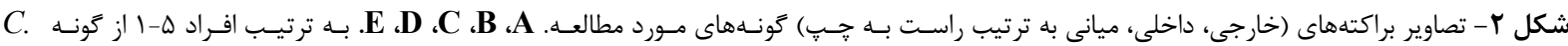

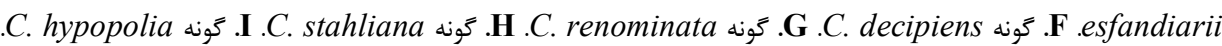

Figure. 2. Photos of the bracts (outer, median, and inner from right to left, respectively) of the studied species. A, B, C, D, E. 1-5 individuals from C. esfandiarii. F. C. decipiens. G. C. renominata. H. C. stahliana. I. C. hypopolia. 

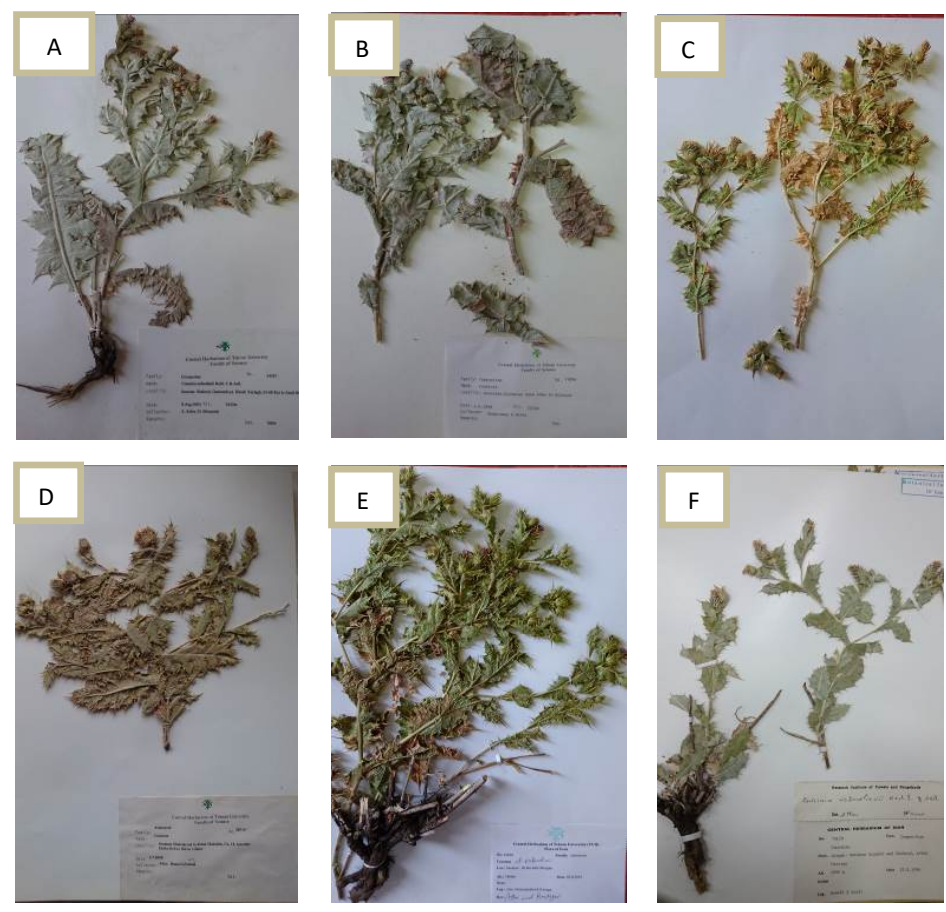

شكل r- تصاوير افراد 9-1 از گونه C. esfandiarii.

Figure. 3. Photos of 1-6 individuals from C. esfandiarii.
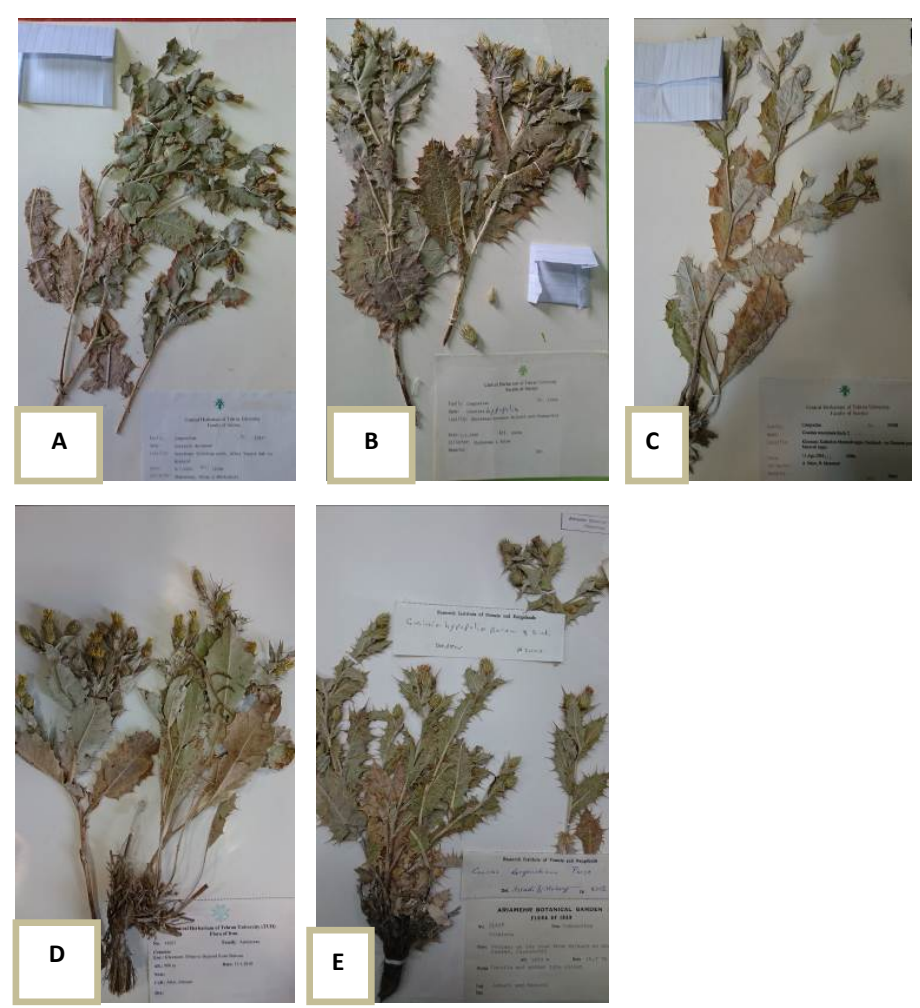

شكل F- تصاوير كونهاى C. daryoushiana :E ،C. stahliana :D ،C. renominata :C ،C. hypopolia :B CC. decipiens :A

Figure. 4. Photos of the species: A: C. decipiens, B: C. hypopolia, C: C. renominata, D: C. stahliana, E: C. daryoushiana 
C. cylindracea var. , Cونسهاى C. alexeenkoana داراى يراكنش در غرب ايران بوده و سيس به مناطق patula

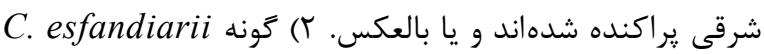

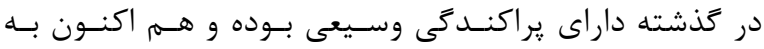
مناطق شرقى و شمال شرقى ايران محدود شده است. هر يكى يك

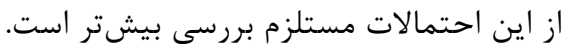
دو كونه C. daryoushiana , C. decipiens كه در فلورا ايرانيكا (Rechinger 1972, 1979) مترادف ذكر شدهاند، بـا

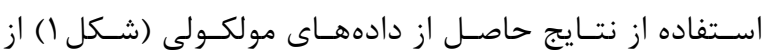
يكديكر جدا قرار گرفتهاند. اين دو گونه از نظر صفات ريخت-

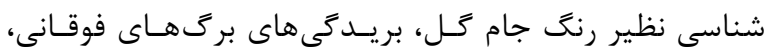

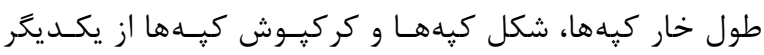

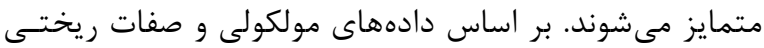

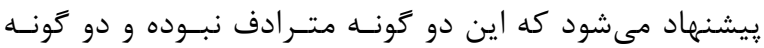

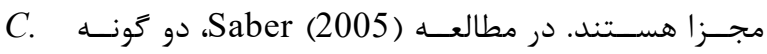
Stahliana

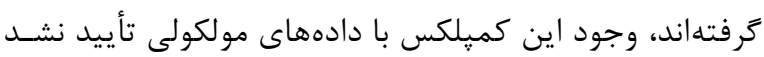

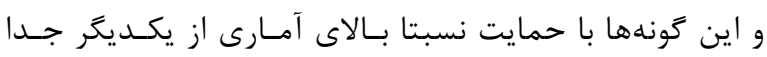
شدهاند.

C. تنوع ريختى مشاهده شده در افراد جمعيتهاى مختلف

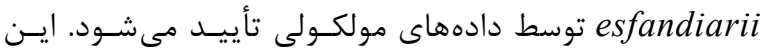

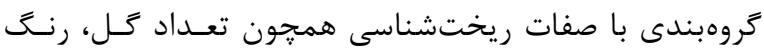
جام كل، شكل كيهها، كركيوش بركَها و شكل خـار انتهايى ردئ

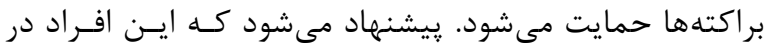

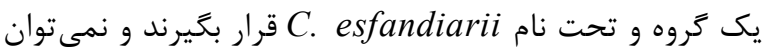

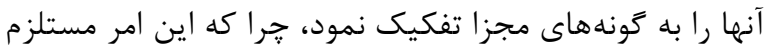
مطالعات بيشتر بر روى افراد جمعيتهاى مختلف ايسن كونـهـ

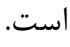

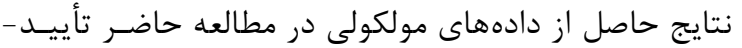

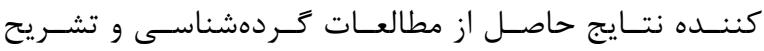

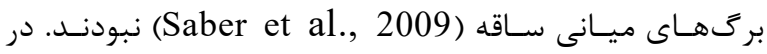
مطالعه با استفاده از دادههاى تركيبى هستهاى و كلرويلاستى

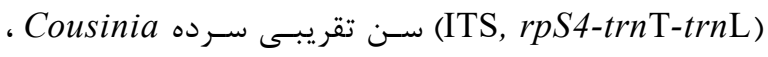

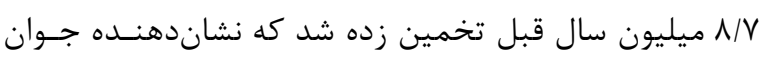

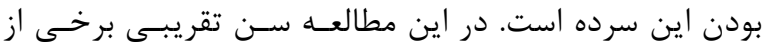

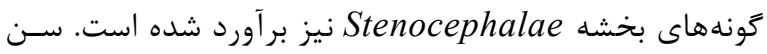

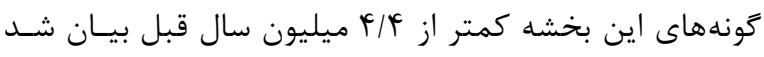

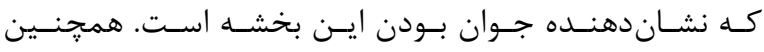

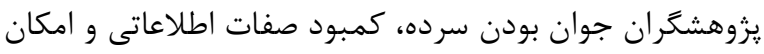

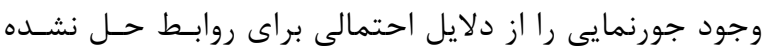

در حاشيه داراى بخشهاى مستطيلى، در طول كوتاهى

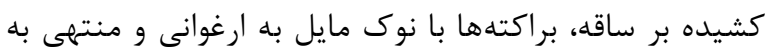

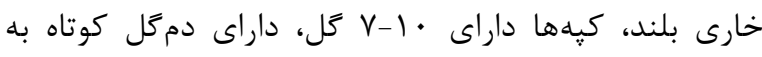

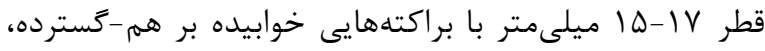

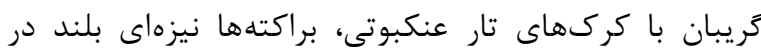

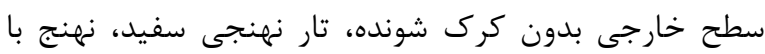

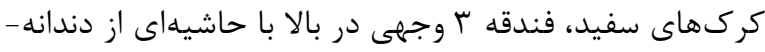

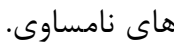

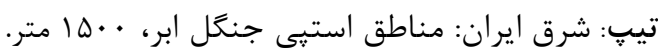
يراكنش عمومى: ايران

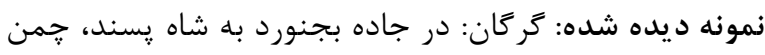
بيد، اسدى و معصومى

بحث

مطالعه بر روى كونسههاى بخشـه Stenocephalae نشـان داد، كونهايى از اين بخشه كه در شمال شرقى ايران يراكنش

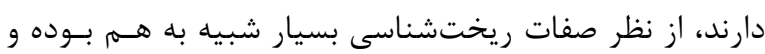
بيدا كردن صفات ريختشناسى كه متمايزكننده ايسن كونسها

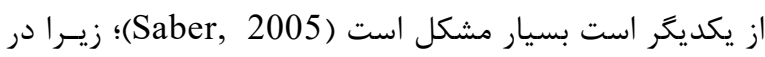

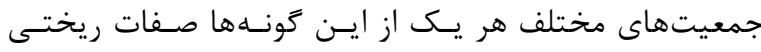
متغير بوده و تنوع ريختى در جمعيتهاى مختلف كَونهها قابل

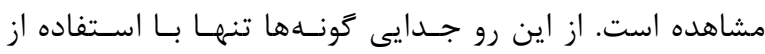

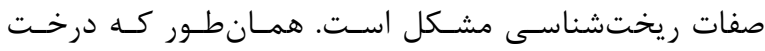
تبارزايشى (شكل () نشان مى دهد، كونههاى مذكور با حمايت

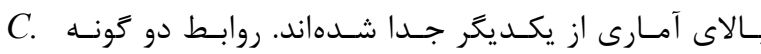
C. daryoushiana renominata كونهاى بررسى شده در اين مطالعه حـل نشـده بـاقى مانــــاه

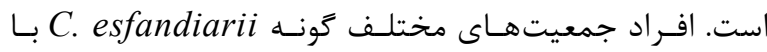

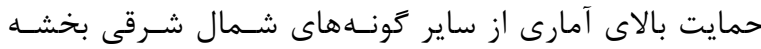
Stenocephalae C. C. decipiens C. C.

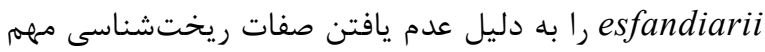

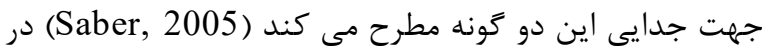

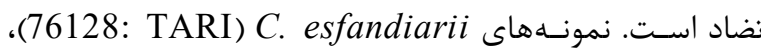
C. cylindracae var. به همراه كونهاى (45830: TUH) patula

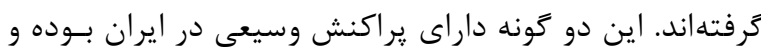

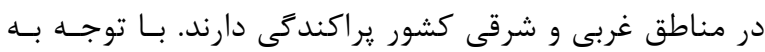

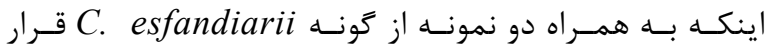

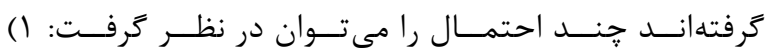




\section{RREFERENCES}

Attar, F., Ghahreman, A., Saber, A. \& Zarre, S. 2005. A new species of the genus Cousinia (Compositae, sect. Stenocephalae) from SW of Iran. Iranian Journal of Botany 11: 65-69.

Attar, F. 2011a. Taxonomic revision of Cousinia sect. Albidae Bunge (Asteraceae) in the flora of Iran. Iranian Journal of Botany 17: 150-157.

Attar, F. 2011b. New taxa of Cousinia Cass., Sect. Stenocephalae Bunge (Asteraceae) from Iran. Taxonomy and Biosystematics 3: 59-68.

Baldwin, B.G \& Marcos, S. 1998. Phylogenetic utility of the external transcribed spacer (ETS) of 18S-26S rDNA: Congruence of ETS and ITS trees of Calycadenia (Compositae). Molecular Phylogenetics and Evolution 10: 449-463.

Borchsenius, F. 2009. FastGap 1.2. Department of biosciences, Aarhus University, Denmark. Published online at http://www.aubot.dk/FastGap_home.htm

Bordbar, F., Baqeri, M. \& Mirtadzadini, M. 2017. New chromosome counts in Cousinia (Asteraceae) from Flora of Iran. Cytologia 82: 485-488.

Djamali, M., Baumel, A., Brewer, S., Jackson, S.T, Kadereit, J.W., López-Vinyallonga, S., Mehregan, I., Shabanian, E. \& Simakova, A. 2012. Ecological implications of Cousinia Cass. (Asteraceae) persistence through the last two glacial-interglacial cycles in the continental Middle East for the Irano-Turanian flora. Review of Palaeobotany and Palynology 172: 10-20.

Djavadi, S.B. \& Attar, F. 2006. Two new species of Cousinia Cass. of sect. Stenocephalae Bunge from Iran. Feddes Repertorium 117: 453-458.

Djavadi, S.B. 2007. New or rare chromosome count in ten species of Cousinia from Iran. Rostaniha 8: 19-27.

Djavadi, S.B. \& Attar, F. 2010. New chromosome counts in the genus Cousinia (Asteraceae, Cardueae) from Iran. Willdenowia 40: 351-357.

Djavadi, S.B. 2012. New chromosome count in Cousinia (Asteraceae, Cardueae) section Cynaroideae and Stenocephalae from Iran. Iranian Journal of Botany 18: 86-93.

Doyle, J.J. \& Doyle, J.L. 1987. A rapid DNA isolation procedure for small quantities of fresh leaf tissue. Phytochemical Buletin 19: 11-15.

Edgar, R.C. 2004. Muscle: Multiple sequence alignment with high accuracy and high throughput. Nucleic Acids Research 32: 1792-1797.

Faris, J.S. Kallersjo, M. Kluge, A.G. \& Bult, C. (1995). Testing significance of incongruence. Cladistics 10: 315319.

Ghaffari, S.M. \& Sanaei Chariat-Panahi, M. 1985. Chromosome count of some angiosperms from Iran. Iranian Journal of Botany 3: 67-73.

Ghaffari, S.M. \& Djavadi, S.B. 1998. Chromosome studies and distribution of nine species of Cousinia section Stenocephlae (Asteraceae) in Iran. Bulletin de la Société Neuchâteloise des Sciences Naturelles 121: 61-68.

Ghaffari, S.M, Susanna, A. and Garcia-Jacas, N. 2006. New chromosome counts in the genus Cousinia (Asteraceae) from Iran. Botanical Journal of the Linnean Society 151: 411-419.
كونـههاى ايسن سـرده دانسـتند. بـهـ دليـل عـدم وجـود عـدد

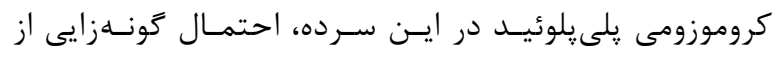

طópez-Viyallonga et ) طريق دوركه (al., 2009

$$
\text { نتيجه گَيرى }
$$

بر اساس مطالعه حاضر، گونـههايى از بخشــStenocephalae

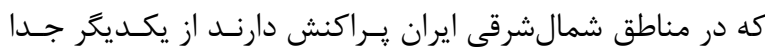

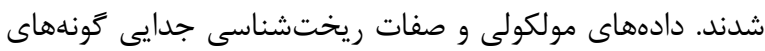

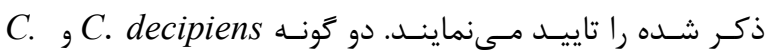
daryushiana بودند در اين مطالعه از يكديخر جدا شدند. جدايى افراد جمعيت-

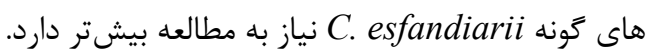

$$
\begin{aligned}
& \text { سياسگزן ارى } \\
& \text { اين يزوهش بخشى از رساله دكتـرى نويســده اول اسـت كـهـ بـاــا }
\end{aligned}
$$

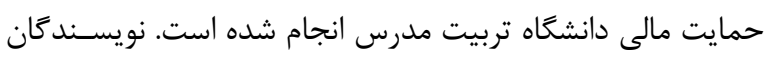

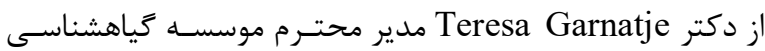

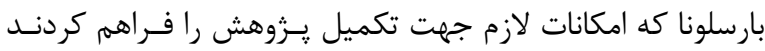

$$
\begin{aligned}
& \text { كمال تشكر را دارند. }
\end{aligned}
$$


Knapp, H.D. 1987. On the distribution of the genus Cousinia (Compositae). Plant Systematic and Evolution 155: 15-25.

Lee, J., Baldwin, B.G. \& Gottlieb, L. 2002. Phylogeny of Stephanomeria and related genera (CompositaeLactuceae) based on analysis of 18S-26S nuclear rDNA ITS and ETS sequences. American Journal of Botany 89: $160-168$.

Linder C.R., Goertzen, L.R., Heuvel, B.V., FranciscoOrtega, J. \& Jansen, R.K. 2000. The complete external transcribed spacer of $18 \mathrm{~S}-26 \mathrm{~S}$ rDNA: amplification and phylogenetic utility at low taxonomic levels in Asteraceae and closely allied families. Molecular Phylogenetics and Evolution 14: 285-303.

López-Vinyallonga, S., Mehregan, I., Garcia-Jacas, N., Tscherneva, O., Susanna, A. \& Kadereit, J.W. 2009. Phylogeny and evolution of the ArctiumCousinia complex (Compositae, CardueaeCarduinae). Taxon 58: 153-171.

López-Viyallonga, S. Romaschenko, K., Susanna, A. \& Garcia-Jacas, N. 2011. Systematics of the Arctioid group: Disentangling Arctium and Cousinia (Cardueae, Carduinae). Taxon 60: 539-554.

Marcos, S. \& Baldwin, B.G. 2001. Higher-Level Relationships and Major Lineages of Lessingia (Compositae, Astereae) Based on Nuclear rDNA Internal and External Transcribed Spacer (ITS and ETS) Sequences. Systematic Botany 26: 168-183.

Miller, M.A., Pfeiffer, W., \& Schwartz, T. 2010. Creating the CIPRES science gateway for inference of large phylogenetic trees. In Proceedings of the Gateway Computing Environments Workshop (GCE), New Orleans, LA, 8 pp, available at: htpp://www.phylo. org.

Nylander, J.A.A. 2004. MrModeltest v2. Program distributed by the author. Evolutionary Biology Centre. Uppsala University, Uppsala.

Parsa, A. 1945. Cousinia in flore de L' Iran. vol. 3. Tehran University Press, pp. 480.

Post, G.E. 1933. Flora of Syria, Palestine and Sinai, vol. II. American University of Beirut, pp. 84-87.

Rechinger, K.H. 1986. Cousinia morphology, taxonomy and phytogeographic implications. Proceedings of the Royal Society. Edinburgh, B., Biological Sciences 89: 45-58.

Rechinger, K.H. 1972. Compositae-Cynareae I: Cousinia. In: Rechinger K.H. (ed.), Flora Iranica vol. 90. Akad. Druck- und Verlagsanstalt, Graz, 329 pp.

Rechinger, K.H. 1979. Compositae-Cynareae III: Cousinia. - In: Rechinger K.H. (ed.), Flora Iranica vol. 139a. Akad. Druck- und Verlagsanstalt, Graz, pp: 105-156.
Saber, A. 2005. Biosystematical studies on the Cousinia section Stenocephalae (Asteraceae) in Iran. M.Sc. thesis, University of Tehran.

Saber, A., Attar, F. \& Djavadi, S.B. 2009. Studies of pollen grains in the sect. Stenocephalae (Cousinia Cass. Asteraceae) in Iran. Iranian Journal of Botany 15: 114-128.

Sang, T., Crawford, D.J. \& Stuessy, T.F. 1995. Documentation of reticulate evolution in peonies (Paeonia) using internal transcribed spacer sequences of nuclear ribosomal DNA: implications for biogeography and concerted evolution. Proceedings of the National Academy of Sciences of the United States of America 92: 6813-6817.

Shaw J., Lickey, E., Schilling, E. \& Small, R.L. 2007. Comparison of whole chloroplast genome sequence to choose noncoding regions for phylogenetic studies in Angiosperms: The tortoise and the hare III. American Journal of Botany 94: 275-288.

Susanna, A. \& Garcia-Jacas, N. 2007. Tribe Cardueae. pp: 123-146 In Kadereit, J.W. \& Jeffrey, C. (eds.). The families and genera of vascular plants, vol. 8 . Flowering plants: Eudicots; Asterales. Berlin, Heidelberg: Springer.

Swofford, D.L. 2002. PAUP*: PAUP*: Phylogenetic Analysis Using Parsimony (*and Other Methods), Version 4.0b10. Sunderland, Sinauer Associates. [Accessed 11 November 2019].

Trifinopoulos, J., Nguyen, L.T., Haseler, A.V. \& Quang Minh, B. 2016. W-IQ-TREE: a fast online phylogenetic tool for maximum likelihood analysis. Nucleic Acids Research. 44: 232-235. Available from: http://iqtree.cibiv.univie.ac.at [Accessed 11 November 2019].

Tscherneva, O.V. 1962. Cousinia Cass. - In: Shishkin, B.K. (ed.), Flora U.S.S.R. vol. 27. Akademiya Nauk, Leningrad; pp: 108-357.

White, J.T., Bruns, T.D., Lee, S.T. \& Taylor, J.W. 1990. Amplification and Direct Sequencing of Fungal Ribosomal RNA Genes for Phylogenetics. In Innis DH (ed) PCR protocols: a guide to methods and applications. Academic Press, San Diego 31: 315-322.

Tscherneva, O.V., Joharchi, M.R., \& Ghahremaninejad, F. 2005. A new species of the genus Cousinia (Asteraceae) from Iran. Botanicheskii Zhurnal 90(3): 411-414

Zare, M., Khossravi, A.R. \& Joharchi, M.R. 2013. Distribution patterns of the genus Cousinia (Asteraceae) in Iran. Iranian Journal of Botany 19: 127-141.

How to cite this article:

Kalouti, S., Kazempour Osaloo, Sh., Attar, F., Susanna, A. \& Garcia-Jacas, N. 2021. Molecular phylogeny and taxonomy of species of Cousinia section Stenocephalae (Asteraceae) in NE of Iran. Nova Biologica Reperta 8: 56-67. (In Persian).

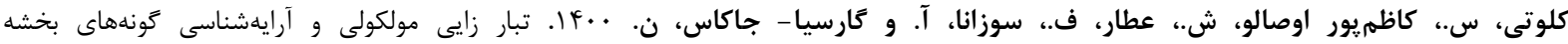

$$
\begin{aligned}
& \text { Stenocephalae }
\end{aligned}
$$

